\title{
SEMEN COMPOSITION AND EJACULATION OF THE BOAR AFTER PILOCARPINE ADMINISTRATION
}

\author{
R. D. BAKER AND P. J. DZIUK \\ Animal Genetics Laboratory, Department of Animal Science, \\ University of Illinois, Urbana, U.S.A.
}

(Received 22nd April 1964)

\begin{abstract}
Summary. Pilocarpine ( $50 \mathrm{mg}$ ) administered to the boar $20 \mathrm{~min}$ before semen collection had no detectable effect on either ejaculation or semen composition. However, the volume of fluid semen, the total volume of semen, and the time required for ejaculation differed significantly $(P<0.01)$ between breeds of boars.
\end{abstract}

Atropine, a parasympathetic-blocking drug, has been found to reduce the volume of semen with little or no effect on the total number of spermatozoa ejaculated by the boar (Dziuk \& Norton, 1962). Differences in composition of the semen from atropine-treated and control boars indicated that atropine suppressed the secretion of the urethral glands (Dziuk \& Mann, 1963).

In the bull, atropine has been found to reduce both the volume of semen and the number of spermatozoa per ejaculate (Signoret, 1962; Baker, VanDemark \& Graves, 1963), whereas pilocarpine, a parasympathetic-stimulating drug, has significantly increased the volume of semen and total spermatozoa per ejaculate (Baker et al., 1963; J. P. Signoret, personal communication).

The purpose of the present study was to determine the effects of pilocarpine on the ejaculatory process and semen composition of the boar. The experimental animals were four purebred, yearling boars, two Yorkshire and two Duroc Jersey, weighing about $450 \mathrm{lb}$. They were injected subcutaneously behind the ear, 20 to $30 \mathrm{~min}$ before semen collection began, with either $4 \mathrm{ml}$ of physiological saline solution or $4 \mathrm{ml}$ of saline solution containing $50 \mathrm{mg}$ of pilocarpine hydrochloride. The interval between collections was 3 or 4 days. Each treatment was applied to each boar four times, so that thirty-two ejaculates were collected.

The semen was collected by grasping the tip of the boar's penis with the bare hand as the boar mounted a dummy. The time required for ejaculation was recorded. Immediately after collection, the total volume of ejaculate was noted. The semen was then strained through gauze to remove the gelatinous material. The volume of fluid was then recorded and the volume of gelatinous material was determined by subtraction. The concentration of spermatozoa was determined with a haemocytometer. 
A copious flow of saliva from the pilocarpine-treated boar, beginning about $15 \mathrm{~min}$ after injection and continuing for about $45 \mathrm{~min}$, indicated that the drug was effective.

Even though $50 \mathrm{mg}$ of pilocarpine greatly stimulated salivation in all boars, it did not significantly affect libido, erection, duration of ejaculation, semen volume, sperm number, or sperm concentration. This is in contrast to the results obtained in the bull that showed pilocarpine increased the volume of semen and number of spermatozoa.

The duration of ejaculation did vary significantly $(P<0 \cdot 01)$ between breeds. Yorkshire boars ejaculated in $4.6 \mathrm{~min}$, while the Duroc boars ejaculated in 7.2 min. The Yorkshire boars also produced a significantly higher volume of fluid semen and total semen than Duroc boars (Table 1). These breed differences

TABLE 1

SEMEN COMPOSITION OF YORKSHIRE AND DUROC JERSEY BOARS AFTER PILOCARPINE TREATMENT

\begin{tabular}{l|c|c|c|c}
\hline \multirow{2}{*}{ Semen composition } & \multicolumn{2}{|c|}{ Treatment } & \multicolumn{2}{c}{ Breed } \\
\cline { 2 - 5 } & Policarpine & Control & Torkshire & Duroc \\
\hline Fluid volume $(\mathrm{ml})$ & 131 & 152 & $172^{*}$ & 111 \\
Gel volume $(\mathrm{ml})$ & 36 & 41 & 43 & 35 \\
Total volume $(\mathrm{ml})$ & 167 & 193 & $215^{*}$ & 146 \\
Sperm per ml $\left(\times 10^{6}\right)$ & 382 & 332 & 312 & 403 \\
Sperm per ejaculate $\left(\times 10^{9}\right)$ & 47.0 & 48.6 & 51.4 & 44.0 \\
\hline
\end{tabular}

* Significantly different, $P<0 \cdot 01$.

are in agreement with previous observations made at our laboratory.

As pilocarpine did not increase the volume of semen ejaculated by the boar in this study, it is supposed that the urethral and bulbourethral glands did not respond to the parasympathetic stimulant by producing additional secretion. A chemical investigation of semen of boars treated with different doses of pilocarpine and other parasympathomimetic drugs would be helpful in understanding the role of the parasympathetic system in the control of male reproduction in swine.

\section{REFERENCES}

Baker, R. D., VanDemark, N. L. \& Graves, G. N. (1963) Drug effects on behavior and ejaculates of bulls. J. Anim. Sci. 22, 136.

DzUIK, P. J. \& MANN, T. (1963) Effect of atropine on the composition of semen and secretory function of the male accessory organs in the boar. F. Reprod. Fertil. 5, $10 \mathrm{I}$.

Dziuk, P. J. \& Norton, H. W. (1962) Influence of drugs affecting the autonomic system on seminal ejaculation. F. Reprod. Fertil. 4, 47.

Signoret, J. P. (1962) Action de l'atropine sur le comportement sexual et la composition du sperme chez le taureau. Ann. Biol. anim. Bioch. Biophys. 2, 2. 